\title{
ATTITUDES OF GIFTED CHILDREN TO PEOPLE WITH DISABILITIES
}

\author{
Eva Urbanovská \\ Adéla Hanáková \\ Ivana Horváthová \\ Pavel Kučera \\ Monika Kunhartová \\ Lucia Pastieriková \\ Vojtech Regec \\ Kateřina Stejskalová \\ Palacký University in Olomouc, Czech Republic
}

\begin{abstract}
Talent is characterized as asynchronous development, which combines accelerated cognitive abilities and increased intensity to create inner experiences and awareness that are different from their quality standards. Article reflects the results of research that aimed to describe the group of exceptionally gifted children aged in terms of their attitudes, opinions and concerns to people with disabilities. To obtain the data was specifically chosen method of focus groups and projective technique unfinished sentences. Target groups were presented unfinished sentences, so that on the basis of the replies received gave to identify topics that are relevant to it. One of the objectives was to find out the answers obtained from the opinions and attitudes towards the phenomenon of disability - to obtain information to enable understanding of the way in which this target group thinks about people with disabilities.
\end{abstract}

Keywords: gifted children, attitude, people with disabilities.

\section{Introduction}

Children who are gifted may be difficult to define and identify without a clear concept of the complex factors and contexts that may be involved in their early development and their resulting characteristics and personalities. Freeman (2013) use the word ,gifted" to mean outstanding cognitive ability and „talented" to mean outstanding artistic ability, though the two do overlap and many in this study enjoyed both. Theorists sometimes juggle with the terms, such as Gagné (1999) who describes ,gifts" as the maturation of „talents” which he sees as potential, or Gardner (1983) who presents the idea of separate „,intelligences" each of which can reach a gifted level independently of the others. There appears to be some agreement about two specific expressions of giftedness (Csikszentmihalyi \& Csikszentmihalyi, 1993; Winner, 2000; Wellisch \& Brown, 2013) and as has been demonstrated, they may be 
accompanied by any number of diverse characteristics with a multitude of possible combinations. The first is the positive, well adjusted, resilient, intellectually gifted achiever, and the second may be anxious, introverted, creative, possibly mathematically or scientifically gifted, and susceptible to both positive and negative experiences that appear to determine level of adjustment and achievement (Belsky, 2005; Dabrowski, 1972; Winner, 2000; Wellisch \& Brown, 2013).

The aim of this study is to outline the attitudes of gifted students towards people with special educational needs. The focus of the research probe just to a group of gifted students was motivated by a high potential of the group and also by the fact that gifted students themselves form a group of people with special needs. The particular research strategy has been chosen with regard to specifics of the target group (age, gift), research goal and characteristics of the observed field. The intention was to create a platform for applied research, to carry out a primary probe along the lines of the selected issue and to verify the options of exploring the attitude of the target group using the selected tool. For this purpose, a specific variant of questionnaire with open unstructured items or unfinished items was created, providing space for free associations in the context of persons with specific needs which were the object of our interest within the research. Using the open form as well as formulating the items through aposiopesis, we tried to eliminate suggestiveness. The method was aimed at having an a priori projective character.

\section{Attitudes toward people with disabilities from perspective of majority population}

Disability is the source of many myths, prejudices and stereotypes. A similar situation is in the field of gifted people, but usually these prejudices have positive message. It's basically a natural - things that people do not understand and which they fear, they try to avoid or downplay it into prejudices and stereotypes. Disability is for society subconsciously threatening - is proof that something can go wrong; is a reminder that good health is not unchanging state (Požár in Regec, Stejskalová et al., 2012). Prejudice and stereotyping is a certain leakage and simplifying subjectively unfavorable situation. Is typical and natural, that the society perceives peculiarities and exceptionality a priori as disturbing, threatening or dangerous - they threaten the need for safety and certainty. Relationship to persons with disabilities is an expression of tolerance for differences, respecting to the individuality of each person and partly a measure of internal quality of individuals and society as a whole. Only if the company, including its individual members, be able to exceed conventions and stereotypes, people with disabilities will not be perceived only from the perspective of disability, whether with a rejection or compassion (Vágnerová, Hadj-Moussová, Štech, 2000). Is this situation also typical for view from 
perspective of gifted children? Perceive them themselves from a similar angle of view?

In attitudes towards persons with disabilities dominates emotional component. For it is characteristic ambivalence - contains both positive and negative emotional experiences. Typical emotional symptoms of laic population include mercy and at the same time awe and aversion. Persons with disabilities acquire, in a social context, the specific role of a disabled person. This role brings certain privileges, but also certain restrictions and limitations. This role is significantly determined by stereotypical attitudes and expectations of society. Rejection of the contents of this role is at odds with generalized social assessment and is socially sanctioned (Vágnerová, Hadj-Moussová, Štech, 2000). The natural tendency of the major population is to reduce the personality of an individual with disability solely on their handicap. Disability becomes the dominant characteristic of the person. This situation is reflected also in selfperceptions of individual, also identity of a person with disability is changed. Attitudes of society, in a certain extent, predetermine role, status and level of integration of this person into society (Vágnerová et al., 2008).

The criteria of beauty and physical fitness, which are set in the society, become an integral part of the self-esteem of a person with disability and the standard by which one measures themselves and others (Matějček, 2009). The socio-psychological dimension takes the form of stigmatization. Stigma is not true quality of human, but is attributed only in the context of attitudes which are typical for the society (Vágnerová, Hadj-Moussová, Štech, 2000). How is this in the context of the young generation, and generation of gifted children? What is their perspective and self-perception in conjunction with persons with disabilities? As part of our research, we attempted to probe the primary intentions of the chosen problem.

It is clear that change in attitudes of lay society towards people with disabilities is a matter of long-term development, which assumes raising awareness in the future generations, so that the issue of disability has ceased to be a source of various taboos, unknown and threatening feelings. Our goal was explore the current situation within the population of gifted children - a population that has significant potential and at the same time is itself a specific group. The main research question was oriented to attitudes of gifted children to the persons with disabilities. In concept of "open area of free associations" we should provide space for semantic analysis of associations related to people with disabilities. It is clear that the findings can not be generalized; however, the data are a source of interesting ideas for applied research.

\section{Methodological Aspects}

In terms of methodology, the non-probability sampling method was used to select the research sample - the method of intentional (purposeful) selection, 
where participants possessing certain features are targeted. The sampling criterion has been a selected feature or an expression thereof, or a condition. On the basis of the parameters determined, respondents were targeted among children (pupils of the primary school first level) with gift (classes for gifted pupils), who were willing to participate in the research. In particular, a simple intentional sampling was used, i.e. selection of willing participants from the group meeting the criteria in question. The resulting research sample comprised 87 respondents. The age structure of the research group corresponded to the first level of primary school with the majority of respondents being between the age of 8 and 10; in terms of gender, the research group contained a majority of boys $(62,1 \%)$. The age and gender structure is illustrated in Table 1 . The presented age structure shows that most of the respondents were aged 8 and 10 years old. In a given age category we expect some awareness about people with disabilities. At the same time we expect a lower level of influence of stereotypical reactions of the majority population.

Table 1. Research group age structure

\begin{tabular}{|c|c|c|}
\hline $\begin{array}{c}\text { Age (in } \\
\text { years) }\end{array}$ & $\begin{array}{c}\text { Number of } \\
\text { responses }\end{array}$ & Percentage \\
\hline $\mathbf{6}$ & 4 & $4.7 \%$ \\
\hline $\mathbf{7}$ & 9 & $10.5 \%$ \\
\hline $\mathbf{8}$ & 24 & $27.9 \%$ \\
\hline $\mathbf{9}$ & 16 & $18.6 \%$ \\
\hline $\mathbf{1 0}$ & 22 & $25.6 \%$ \\
\hline $\mathbf{1 1}$ & 7 & $8.1 \%$ \\
\hline $\mathbf{1 2}$ & 1 & $1.2 \%$ \\
\hline $\mathbf{1 3}$ & 1 & $1.2 \%$ \\
\hline $\mathbf{1 4}$ & 2 & $2.3 \%$ \\
\hline
\end{tabular}

\section{Data Analysis and Interpretation}

The free association area focused on associations connected with disabled persons in general has shown certain attitudinal characteristics of contemporary society which are already projected into perception of the youngest population. It is encouraging that some of the responses have a desirable form: „they are often deprecated or underestimated in our society. Disability is not their fault and in most cases, they have learned how to live with it, so we shall not think anything bad about them"; ,they are the same as us but the people see them differently because of their disability"; „they are often more humble and appreciate things like hearing, health and sight"; sometimes they are nicer than some people without disability"; ,the same as us, but they are still discriminated"; ,sometimes they are pushed out of the society".

Furthermore, there were several quite concise answers, corresponding to the specific state of thought in the particular age (,,people with some illness or 
fracture"; „normal people who are limited by their disability, often underestimated but they can achieve a lot"; „totally normal people who have some restrictions"). However, several reactions appeared suggesting a strong cognitive component of the attitude (even if sometimes with persisting inappropriate terminology) - ,people with mental, physical or sensual disability”; „for example blind, deaf, in a wheelchair”; ,invalid”; „blind, deafand-dumb, etc."; ,they were born like that". Within this component, it is also possible to trace several typical mistakes in social learning - e.g. implicit personality theory (,good and polite”). In the semantic structure, also terms from the opposite pole of the spectrum appeared which we are currently trying to eliminate in the majority society (poor, helpless, vulnerable, wretch, restricted). However, misunderstanding was considerably reflected in this item, which resulted in answers such as "handicapped, disabled, ill, disadvantaged”. In seven cases, this situation was manifested by omitting the item. How is otherness perceived by the gifted children? This may be suggested by the polarity responses - „other than normal" versus ,the same as us"; „normal” versus ,different". However, one of the response variants has a very positive tone - people with disability are perceived simply as ,people”.

The next item (I think that people with disability...) has further extended the circle of free associations, inter alia, by interesting positively toned responses emphasising the aspects of equivalence, equality, tolerance, social inclusion, frequently accenting the issue of help: ,, are a bit different, but you can have a lot of fun with them"; ,are not different and have the same rights as others"; ,are often excluded from society”; „shouldn't be underestimated”; „shouldn't be educated in special institutions"; ,should be given more respect”; „shouldn't be deprecated". Also, a differentiated perception of the disability situation appeared, presented by the response ,have both, advantages and disadvantages". The opposite pole of the association spectrum presents the generalizing responses such as ,are very unhappy”; „do not have a good life”; „do not have an easy life”; ,are weird”; „it's bad for them”. We will leave the following answers uninterpreted: ,should try to be like normal”; ,should receive presents"; ,see the world differently".

The next items focused on perception of people with specific type of health disability. Along the lines of associations connected to hearing impairment, a broad spectrum of responses was recorded with a number of them having a very positive character, not only in terms of attitude but also the information contained (regarding the cognitive component of the attitude): „I guess they have great problems with communication"; ,must focus on facial expressions and gestures"; „often can't learn to speak and have problems to communicate (most people can't use the sign language"); „have to learn the sign language - I guess it is, more difficult than written alphabet”; ,may learn how to lip-read and thus communicate with others"; ,it's difficult for them but for the others talking to them as well". Most frequently, connection with the "Sign Language" 
appeared along with necessity to master it. In this item, the persistent inadequate terminology was reported - deaf, deaf and dumb. Also here, we leave it to the reader to interpret two specific entries: „will never be able to hear music”; „I'm sorry for these people even if I think that sometimes it is better not to hear what people say."

The item dedicated to unsighted persons has brought answers very similar to the previous item in terms of structure: „can't see the beauty of this world but on the other hand, can't see the bad, evil, either”; ,need a guide dog, white stick and help of the sighted people"; ,it's very difficult for them because sight is the main sense of our body"; ,need to walk with a white stick outside”; ,are blind”; „are unsighted (visually impaired)"; „hear well and have good sense of touch”; „read using the Braille alphabet”; ,are happy they can hear”; ,are blind forever”. To summarize the statements above, especially the issues of space orientation, utilization of compensation mechanisms and necessity to use guide services were mentioned. We can also register the occurrence of several deep-rooted myths - "have excellent musical ear and they should play violin, for example"; „live in eternal darkness and therefore we have to help them”.

The next item observed the associations connected to a person in a wheelchair. Likewise, the impacts of limited mobility on the person's everyday life were accented here, mentioning the spare time activities, especially sports and options of applied physical activities (,can do different sports thanks to special equipment”), the questions of help appeared as well (,I should help them"; „need someone by their side" etc.). The structure of the following answers was more or less similar to the previous item. Again, we provide several statements which stand out of line: „movement is difficult for them, however they can manage everything else like others"; „can be great people even without legs"; ,are in a wheelchair but otherwise they are completely normal"; "can have skilful hands”; ,are no different from us"; „,need to have fun".

Attitudes toward persons with communication disorders were also included in the frame of reference. According to the addressed gifted children, what is a person who stutters like? It should be noted that in 17 cases, the respondents were not sure how to answer, with the remaining answers referring to the impairment of speech, not the person's dignity - ,definitely do not deserve contempt. If other, normally speaking people, will behave nicely to them, their condition may improve"; ,it is difficult to understand them but we have to behave so that they don't feel like ill”; ,can try to tackle it and eliminate it”; ,,are often mocked because they speak unclearly". Here, too, we see a relatively strong cognitive component of the attitude - „experienced some shock or they were born like that”; ,are completely normal, stuttering is the same as if someone can't pronounce „r"; ,need more time for speaking”; „should visit a speech therapist”; „,can't speak fluently”. The remaining statements repeated the characteristics such as speech disorder, speech sound disorder, fluency disorder, 
along with normality and necessity of patient approach. We also mention two specific reactions to the unfinished sentence „A person who strutters ... ,is funny but I won't laugh at him"; ,is not disabled for me”. We also recorded innovative terminology - a person with balbuties according to some gifted children is a „koktalín” or „koktavec” (it could be translated as “stutterer”).

In the next item dedicated to persons with autism, unfamiliarity with this term was manifested - 68 respondents could not react to this item and 5 others did not know what the term means. However, if the gifted respondents did react, their responses were very mature: ,are exactly the same as us, only have their habits they sticks to"; „often have different abilities in which they are better than others"; ,it is difficult to answer because each autistic person is different”; „can't accept changes, they want to have everything as it is"; ", have problems talking to people"; ,have problems to make friends"; „it's not their fault". Next, we provide three humorous interpretations corresponding to children's fantasy and spontaneity - an autistic person is an ,autismist”, ,someone who drives a car" or „,has a car” (note: ,auto” means a „car” in Czech).

The difficulty and help aspects were emphasized in the item aimed at making the respondents' answers subjective. Their reactions corresponded to our assumptions - in a substantial majority of cases, the personality of a disabled individual is reduced to the need for help (however, in one case in a surprisingly broad meaning - ,we should definitely help them to integrate into society"). The second most frequent tendency of the participants was an assumption of difficult life. The following three statements are left without interpretation, for the reader's subjective reflection: people with disability ... „often encounter misunderstanding and stupidity of others”; „I wish them that their disability didn't exist”; „I wish them good luck”.

The last item observed, what the people with disability should (People with disability should ...). From the broad spectrum of answers which in general emphasized the necessity to help, to use help as well as the need of respect and equal approach, we select those, the tone of which went beyond our expectations or were specific in some way: ,stop being ashamed of their condition and try to mix with others"; „be considerate to others and show that they really need help”; „stop using their handicap to avoid responsibilities"; „be in a hospital or at home in bed"; ,have the same recognition as other people”; "have opportunity to live a full life"; „enjoy life whatever it is like”; „be protected against maltreatment”; „have the feeling that they are normal”; ,stay as they are”; ,respect the world around them”; „take care of themselves”; „discover their talents”; „be recognized"; „, be happy” or „have a minister”.

Last but not least, we were interested in self-reflection of the respondents, their attitude to themselves, as the category of gifted (,The biggest problem of gifted children is ..."). Intentionally, we included this item as the penultimate one, to have it perceived in the context of persons with specific needs. The structure of responses was very heterogeneous, mostly emphasizing the aspects 
of behaviour and social dimension of the gift:"that even if they are brilliant in various fields, they have troubles with ordinary things"; „I don't know about any problem concerning gifted children only"; ,that they can't realize how lucky they are"; "to love themselves for being healthy"; ,that they want to be the same as others"; „,communication with other children"; „to find a friend”; „the presentation of their gift"; "to socialize”; "different for each one of them"; „boredom” and very concisely said „IQ”. However 32 children could not react to this item.

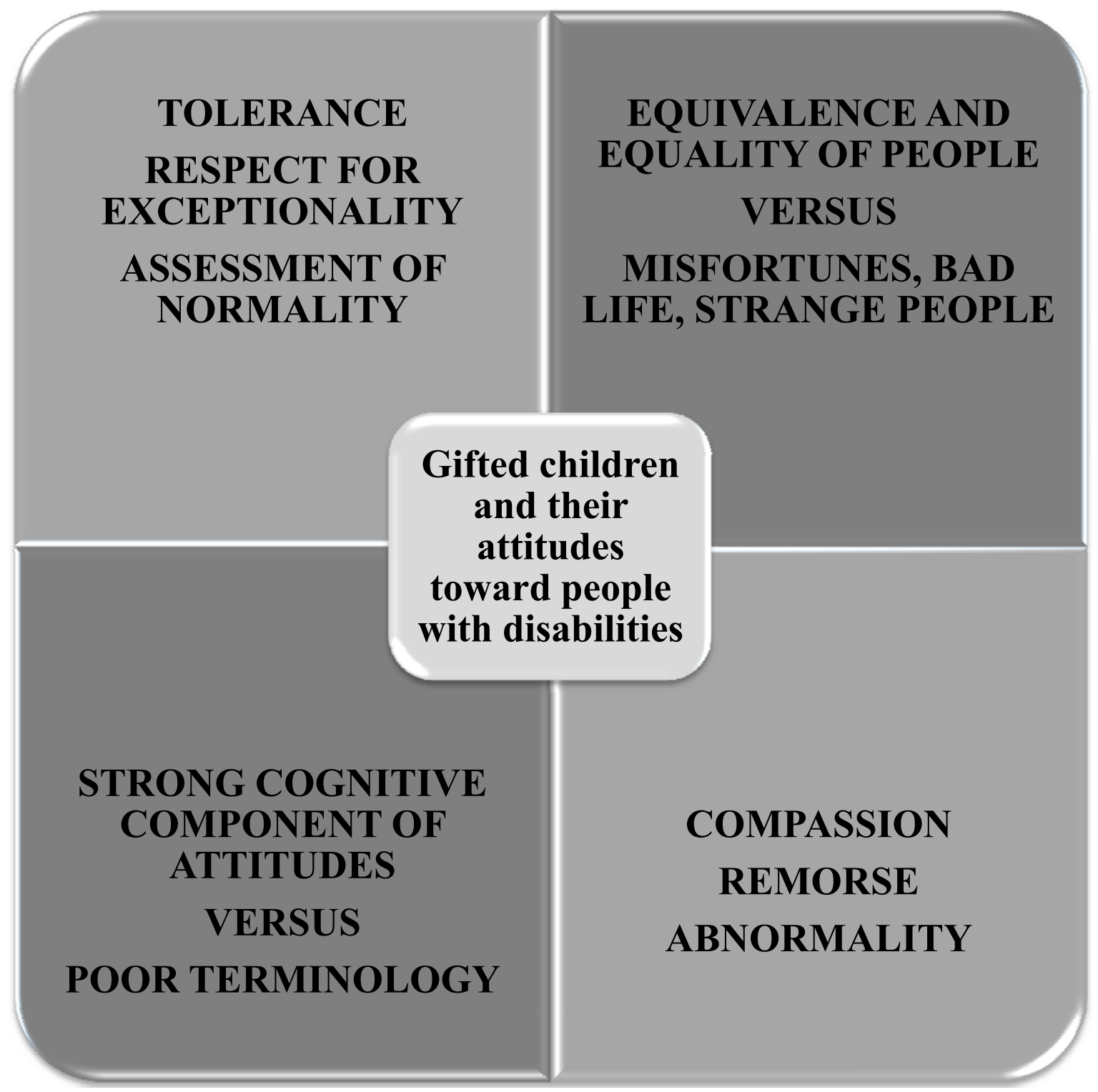




\section{SOCIETY. INTEGRATION. EDUCATION. Volume III}

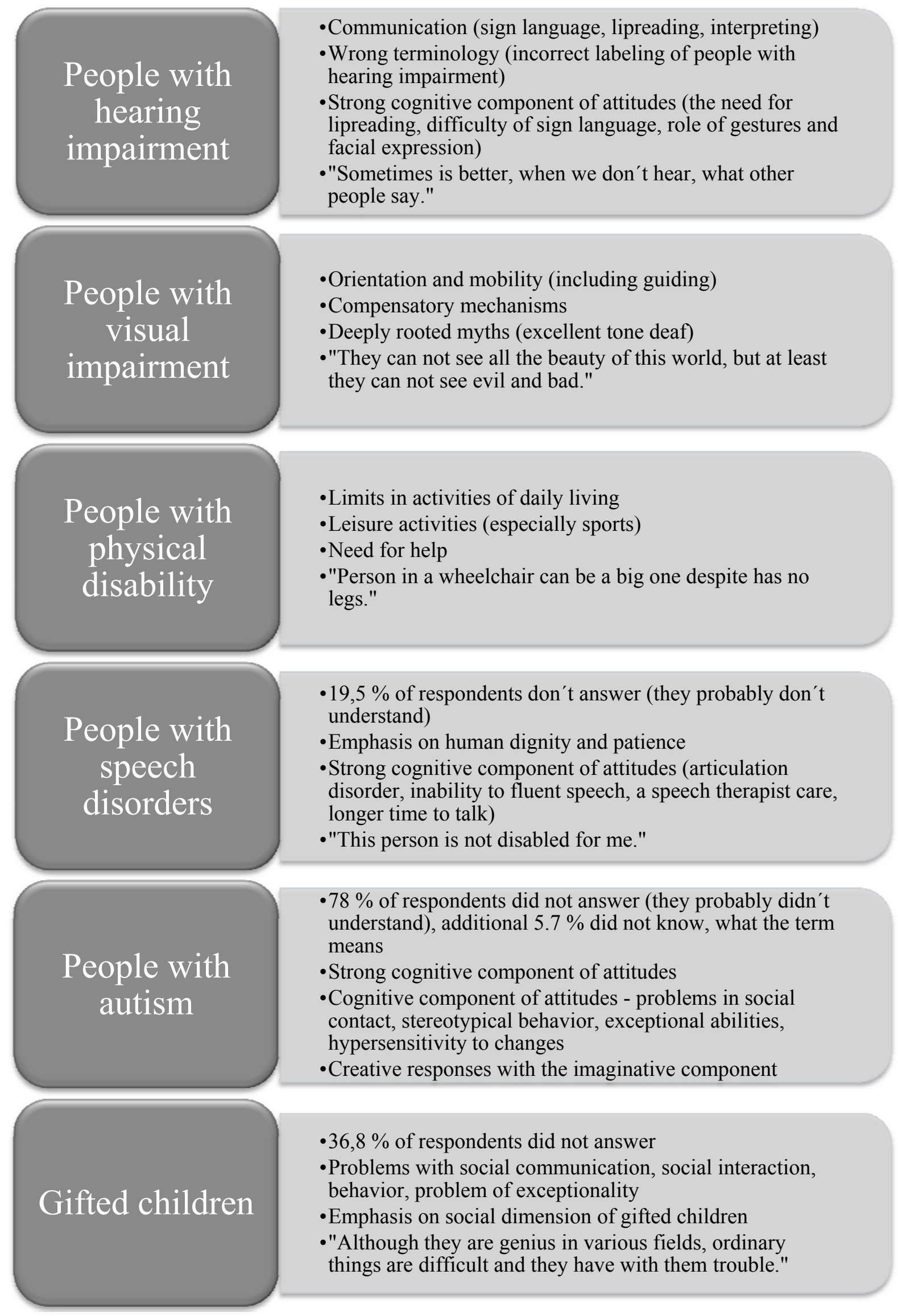




\section{Conclusion}

The aim of this study was to outline the attitudes of gifted students towards people with special needs. The focus of the research probe just to a group of gifted students was motivated by a high potential of the group and also by the fact that gifted students themselves form a group of people with special needs.

In the field of attitudes of gifted children toward people with disabilities we are striving for recognition of specific features. We are interested in how people with disabilities are viewed from the perspective of gifted children and also whether they consider themselves to be people with special needs. Character of their responses is shown in the chart above.

Qualitative data analysis shows many positive aspects. In the target group was, in general, very strong cognitive component of attitudes towards people with disabilities. By contrast of expression of sympathy were given aspects of tolerance, respect and normality. However, we have also encountered with persistent myths and inappropriate compassion and generalization.

We can say that the target group has significant potential to improve the overall attitude of society towards people with disabilities. However, it must be consistent effect not only on gifted children, but on society as a whole.

Attitude of the general public towards persons with disabilities and their transformation is a question of long-term development, which assumes raising awareness of future generations. Is there diference in this question between gifted and non-gifted students or goes development in this area hand in hand with the situation in the entire society?

Outcomes of our research can not be fully generalized, so we present here also a relationship to theory and further research activities.

Free associations of gifted students pointed out some of the attitudinal characteristics of contemporary society - focus on the medical aspect and a tendency to pity or compassion. This persistent attitude is also mentioned by Kaffemaniene \& Jureviciene (2013). In the free association, there are also reaction, which indicates a significant cognitive aspect of personality, as well as positive statements emphasizing aspects of equivalence, equality, tolerance and social inclusion. Respondents accentuated the question of aid and expression of empathy with people with special needs very often. In keeping with associations' related hearing impairment, visual impairment and limitation of motor skills, reactions have a positive character, not only in quetion of attitude, but also in question of the contained information. Again, there is showen a significant cognitive aspect of personality of gifted student. In case of the association on the issue of communication disorder and autism spectrum disorders, there was mainly reflected a lack of information about the issue and the impossibility of expressing it. On the other hand - if the students had awareness about autism, this awareness was very apt. These associations reflect not only cognitive, but also attitudinal maturity. In the case of communication 
disorder, as well as associations related to visual impairment, hearing impairment and limitation of motor skills, there are showen mostly positive attitudes and effort to support. Finally, we were interested in self-respondents, their attitude toward themselves, the gifted category. The structure of the answers were very heterogeneous, most were highlighted aspects of behavior and the social dimension of talent. The associations were again very mature and poignant. But not all students were able to reflect this.

Overall, we can interpret attitudes of gifted students towards people with special needs in our study as a thoroughly positive, although with occasional persist of medical perception. Evident is, however, a significant cognitive aspect of personality and high degree of empathy of gifted students (as confirmed Shechtman \& Silektor, 2012; Eklund et al. 2014), due to which many associations gifted students are mature, concise and pertinent, expressing a certain level of sensitive perception and approach, but not in the sense of unwanted sympathy and pity.

Instead of final summary, we would like to use a quote from one of the participants - „In our society, people with disabilities are often deprecated or underestimated. Disability is not their fault and in most cases, they have learned how to live with it, so we shall not think anything bad about them." The aim of this study was not to provide a comprehensive survey about attitudes of gifted pupils but to open space for further exploration of attitudes of gifted people to other groups of individuals with special needs. We believe that this is some sort of prototype of further development of attitudes of healthy population towards person with special needs.

Acknowledgements. This research was carried out by the Institute of Special Education Studies, Palacký University Olomouc, with the support from the Project „Value of education description of selected factors at students with impairments I. - Education and its value as a factor in students' attitudes to training" - (IGA_PdF_2015_013).

\section{References}

Belsky, J. (2005). Differential Susceptibility to Rearing Influence: An Evolutionary Hypothesis and Some Evidence. In B. J. Ellis, D. F. Bjorklund, B. J. Ellis, D. F. Bjorklund (Eds.) , Origins of the social mind: Evolutionary psychology and child development (pp. 139-163). New York, NY, US: Guilford Press.

Csikszentmihalyi, M., \& Csikszentmihalyi, I. (1993). Family influences on the development of giftedness. Ciba Foundation Symposium, 178187-200; discussion 200.

Dabrowski, K. (1972). Psychoneurosis is not an illness. London, England: Gryf.

Eklund, K., Tanner, N., Stoll, K., \& Anway, L. (2014, August 11). Identifying Emotional and Behavioral Risk Among Gifted and Nongifted Children: A Multi-Gate, Multi-Informant Approach. School Psychology Quarterly. Advance online publication. http://dx.doi.org/10.1037/spq0000080

Freeman, J. (2013). The long-term effects of families and educational provision on gifted children. Educational \& Child Psychology, 30(2), 7-17. 
Gagné, F. (1999). My convictions about the nature of abilities, gifts, and talents. Journal for the Education of the Gifted, 22, 109-136.

Gardner, H. (1983). Frames of mind: The theory of multiple intelligences. New York: Basic Books.

Kaffemaniene, I., \& Jureviciene, M. (2013). Structure and directiveness of attitudes to disability. Social Welfare Interdisciplinary Approach, 3(2), 70-86.

Matějček, Z. (2009). Výbor z díla. Praha: Karolinum. ISBN 978-80-246-1056-6.

Shechtman, Z., \& Silektor, A. (2012). Social competencies and difficulties of gifted children compared to nongifted peers. Roeper Review: A Journal on Gifted Education, 34, $63-$ 72. doi:10.1080/02783193.2012.627555

Vágnerová, M. (2008). Psychopatologie pro pomáhající profese. Praha: Portál.

Vágnerová, M., Hadj-Moussová, Z., Štech, S. (2000). Psychologie handicapu. Praha: Karolinum.

Wellisch, M., \& Brown, J. (2013). Many Faces of a Gifted Personality: Characteristics Along a Complex Gifted Spectrum. Talent Development \& Excellence, 5(2), 43-58.

Winner, E. (2000). The origins and ends of giftedness. American psychologist, 55(1), 159169. 